\title{
A Lucky Open Rib Fracture After Falling from a Donkey
}

\author{
(D) Hüseyin Fatih Sezer ${ }^{1}$, (1) Hakan Dayanır ${ }^{2}$ \\ ${ }^{1}$ Clinic of Thoracic Surgery, Nyala Sudan Turkey Training and Research Hospital, Nyala, Sudan \\ 2 Clinic of Anesthesia and Reanimation, Nyala Sudan Turkey Training and Research Hospital, Nyala, Sudan
}

\begin{abstract}
Open bone fractures are frequently seen in fingers (45\%) and in long bones such as tibia and fibula (11.2\%). Open fractures of the thorax due to rib fracture rarely result in antagonism. Rib fracture treatment is often conservative, but fracture-related complications may require surgical intervention. We presented a case report of a child who had open rib fracture in the left hemithorax after falling from a donkey and who was followed up by the family for a long period of time falsely, considering that it was a piece of wood. There was a story of a 9 years old female patient falling from a donkey 20 days ago. After the trauma, a hard, creamy colored piece of rib extending out about $2 \mathrm{~cm}$ from the surface of the skin in the patient's left hemithorax was thought to be a foreign body by the family. After the tetanus vaccination was performed, the necessary antibiotic treatment was started and the rib piece about $6 \mathrm{~cm}$ in length was removed under local anesthesia. Follow-ups were normal and no complications are encountered yet. As a result, chest wall should be intervened early to reduce or eliminate morbidity in compound rib fractures. Although initiation of treatment in the late period may reduce the chances of success of treatment, morbidity can be reduced by appropriate surgical intervention.
\end{abstract}

Keywords: Rib fracture, open fracture, trauma

\section{Introduction}

Open bone fractures are frequently seen in fingers $(45 \%)$ and in long bones such as tibia and fibula (11.2\%) (1). Open fractures of the thorax due to rib fracture rarely result in antagonism. Rib fracture treatment is often conservative, but fracture-related complications may require surgical intervention (2). Open fractures are complex injuries involving both the bone and the surrounding soft tissues (3). It can cause loss of function in the area where the fracture occurs because it is feared that infection may occur in the open fracture site (4). There are several precautions with the aim of preventing thoracic wall infections; the surgical removal of infected tissues, the use of appropriate and effective antibiotics, and the occlusion of the remaining defect surgically or with secondary healing (5). Beginning the treatment in late period will reduce the chance of successful therapy.

We presented a case report of a child who had open rib fracture in the left hemithorax after falling from a donkey and who was followed up by the family for a long period of time falsely, considering that it was a piece of wood. At the end, a rib fragment extending out of the skin was removed by surgical intervention in our hospital with no significant complication.

\section{Case Report}

There was a story of a 9-year-old female patient falling from a donkey 20 days ago. After the trauma, a hard, creamy colored piece of a rib extending out about $2 \mathrm{~cm}$ from the surface of the skin in the patient's left hemithorax was thought to be a foreign body by the family. Over time, infectious debris in a small amount gathered on that part of rib outside the skin, seemed like a green and cream color and it was thought that this was a foreign body, a piece of wood with the prejudice as a result of history taken from the family. In the physical examination of the patient who applied to our hospital for removal of the supposed-foreign body, there was a partial pectus excavatum except for current condition (Figure 1). Auscultation was normal. 


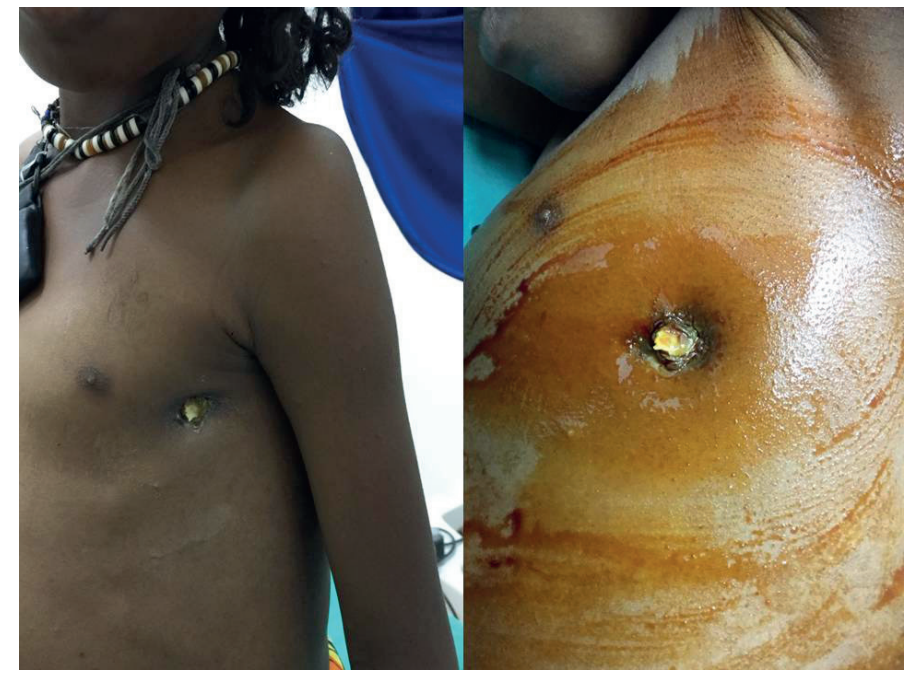

Figure 1. Patients admission

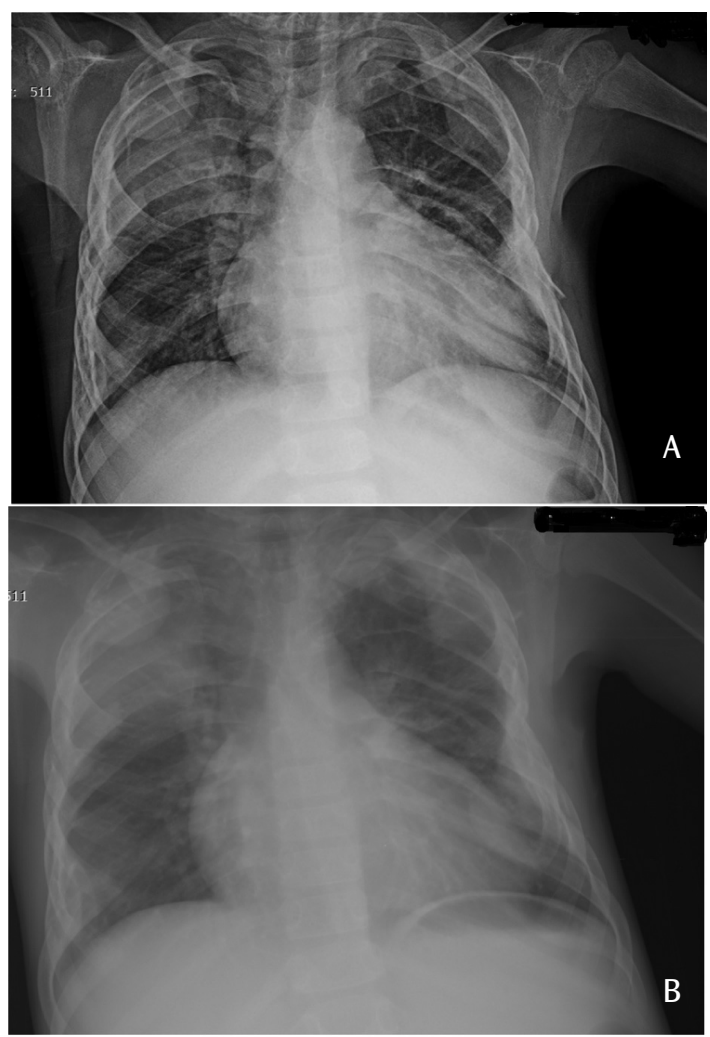

Figure 2. a) First chest X-ray. b) After removal

Leukocytosis, elevation of CRP and deep anemia were present in laboratory tests. On chest X-ray, there was a foreign body appearance in the same opacity as the ribs that went out of the skin on the lateral side of the $5^{\text {th }}$ rib in the left hemithorax. There was no pneumothorax or hemothorax but bilateral rib fractures and cardiomegaly were present with multiple callus tissues (Figure 2a). In thorax CT, it was understood that this was a part of a rib outside the skin after the depletion fracture in the $5^{\text {th }}$ rib (Figure 3a, 3b). After the tetanus vaccination was performed,

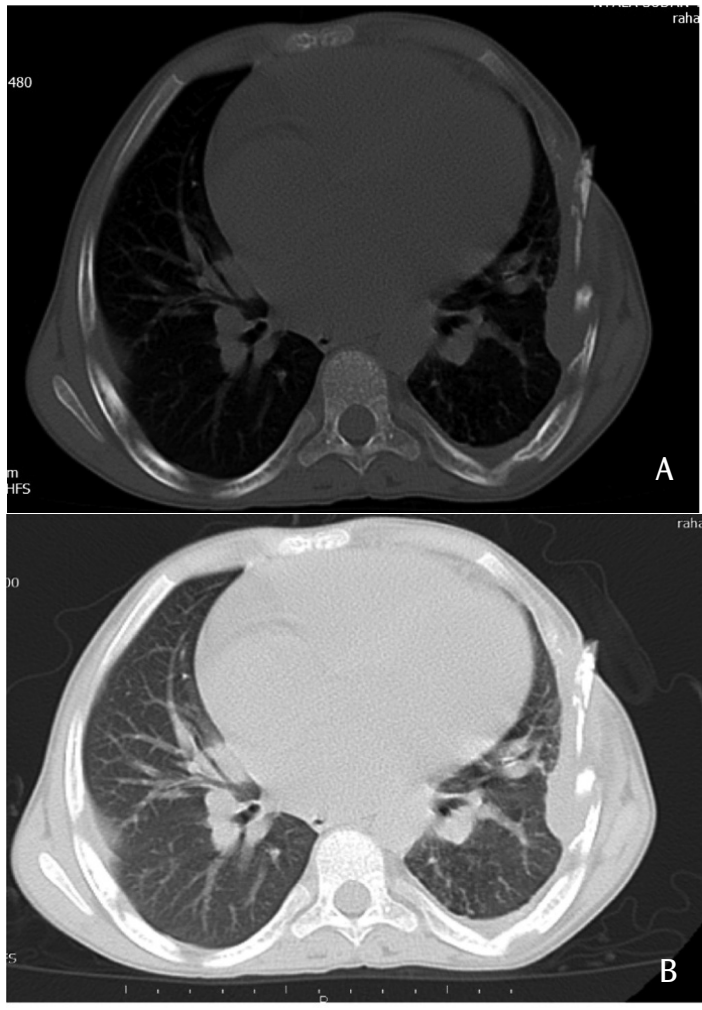

Figure 3. Thorax computed tomography scan

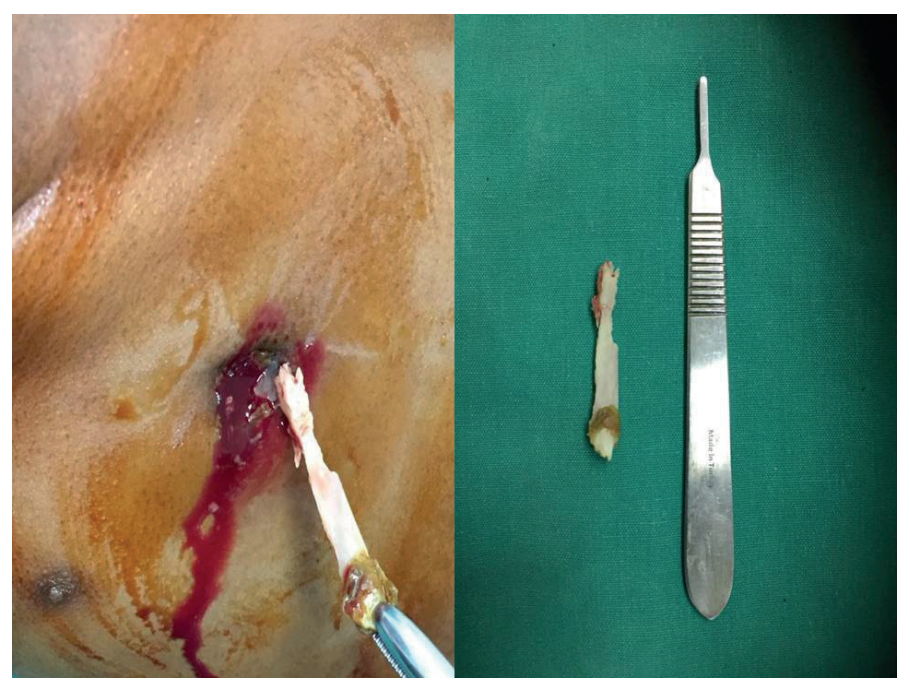

Figure 4. Broken rib

the necessary antibiotic treatment was started and the rib piece about $6 \mathrm{~cm}$ in length was removed under local anesthesia (Figure 4). The necrotic tissue in the skin was debrided and the skin was closed without any flapping. There were no complications after the procedure. No new pathology was observed in postprocedural lung X-ray (Figure 2b). The patient was followed up for 3 days in the pediatric service with the aim of medical treatment and anemia after discharge. Follow-ups were normal and no complications are encountered yet. 


\section{Discussion}

Although rib fractures are common in thoracic trauma, more than $40 \%$ of patients who have thoracic trauma experience rib fractures (6). In the child age group, rib fractures are less common due to the elasticity of the ribs. Pain is frequently observed after rib fractures and pain increases during thoracic movements (7). In our pediatric age group, multiple rib fractures were present and there was pain while breathing and coughing. Rib fracture can be diagnosed by chest X-ray and thorax computed tomography (CT). It should be kept in mind that $50 \%$ of rib fractures can be ignored in PA graphs (7). Despite the presence of rib fractures in chest $X$-ray as radiological examination of the patient, thoracic CT was useful in order to understand the foreign body characteristics of the chest wall and to determine if there was a penetration to the thorax. In thorax $\mathrm{CT}$, it was found that the foreign body on the chest wall was opaque to the same level as the rib and that it was located on the chest wall, did not pass the parietal pleura, and was a part of the rib fracture. Furthermore, thorax CT had multiple rib fractures with bilateral callus formation. After rib fracture, vital preventive complications such as hemothorax, pneumothorax, parenchymal laceration, flail chest may occur, but these complications were not seen in our patient.

Compound fracture is often found in the limbs, thoracic compound ones due to rib fractures are rarely emerges. There is not enough data in the literature to indicate the frequency of compound rib fracture. In our patient, compound rib fractures and callus tissues due to the fall of the cargo animal from the anterolateral of the left hemithorax to the outer skin were formed by a part of the $5^{\text {th }}$ rib and other bilateral multiple rib fractures were present.

Although rib fracture treatment is often conservative, fracturerelated complications may require surgical intervention (2). Compound fractures are complex injuries involving both the bone and the surrounding soft tissues (3). It is feared to have an infection in the compound fracture because it may cause loss of function in the region (4). In order to prevent the thorax wall infections; the surgical removal of infected tissues, the use of appropriate and effective antibiotics, and repairing of the remaining defect surgically or with secondary healing will be considered as possible options (5). Beginning the treatment in the late period will reduce the chances of success. Our patient applied after 20 days of compound rib fracture and there was no other thoracic pathology. In order to prevent infection and not to disturb chest wall stability, the rib piece and surrounding dead tissue were removed by debriding, which lost its vitality, appropriate antibiotic started, tetanus prophylaxis was performed and the defect was primary. Despite the late admission of the patient, the patient could be followed without complication by appropriate surgical procedure. Luckily, there was not any thoracic pathology associated with the compound rib fracture or significant soft tissue infection, except for other rib fractures before the patient had a chance to consult.

\section{Conclusion}

As a result, chest wall should be intervened early to reduce or eliminate morbidity in compound rib fractures. Although initiation of treatment in the late period may reduce the chances of success of treatment, morbidity can be reduced by appropriate surgical intervention.

\section{Ethics}

Informed Consent: Consent of the family was obtained also to present the care process as a case report.

Peer-review: Externally peer-reviewed.

\section{Authorship Contributions}

Surgical and Medical Practices: H.F.S., H.D., Concept: H.F.S., H.D., Design: H.F.S., H.D., Data Collection or Processing: H.F.S., H.D., Analysis or Interpretation: H.F.S., H.D., Literature Search: H.F.S., H.D., Writing: H.F.S., H.D.

Conflict of Interest: No conflict of interest was declared by the authors.

Financial Disclosure: The authors declared that this study received no financial support.

\section{References}

1. Sop LJ, Sop A. Fracture, open. StatPearls [Internet]. Stat Pearls Publishing.2017.

2. Apikogulları B, Yoldas BA, Esme H. Rib Fractures Requiring Surgical Repair: A Case Report. JEMCR 2011;2:23-5

3. Zalavras CG1, Patzakis MJ. Open fractures: evaluation and management. J Am Acad Orthop Surg. 2003;11:212-9.

4. Diktaş H, Öncül O. Overview of Infection Prophylaxis and Antibiotic Treatment in Open Fractures. Turkiye Klinikleri j Orthop \& Traumatol-Special Topics. 2014;7: p. 22-26.

5. Demiroz MS, Findik G. Chest Wall Infections. Turkiye Klinikleri J Orthop \& Traumatol-Special Topics. 2018;9:44-49.

6. Guitron J, Huffman LC, Howington JA, LoCicero J III. Blunt and Penetrating Injuries of the Chest Wall, Pleura, and Lungs. In: Shields TW, Locicero J, Reed CE, Feins RH, eds. General Thoracic Surgery. 7th ed. Philadelphia: Lippincott Williams \& Wilkins; 2009. p. 891-902.

7. Kantarcıoğlu Ö, Şahin E. Gögüus duvarı travmalarına yaklașım. In: Özyurtkan MO, Bostancı K, Özpolat B, (Eds). Toraks Travması.1 st ed. Ankara: Nobel Tıp Kitapevleri; 2018. p. 157-163. 